\title{
Cotidiano
}

\section{A INDISCIPLINA NA SALA DE AULA}

Maria Cláudia Rodrigues de Lima (1)

Silvana Santos Filgueiras (2)

Patrícia Lima Cordeiro (3)

\section{Resumo}

Proponho discutir neste artigo aspectos referentes à indisciplina no ambiente da sala de aula, abordando fatores que podem desencadeá-la, bem como sugerindo propostas que sirvam como redutores deste, que é considerado um dos maiores problemas enfrentados hoje pelos docentes neste espaço. Com este estudo, somos chamados a uma reflexão na busca de possíveis mudanças na atuação, possibilitando uma transformação da conduta na sala de aula.

Palavras-Chave: autoridade, respeito, mudança, indisciplina.

\section{Introdução}

Segundo o dicionário Aurélio, indisciplina é desobediência, falta de disciplina, é o conjunto dos regulamentos destinados a manter a boa ordem em qualquer organização. Deriva originariamente da palavra "discípulo" que significa pessoa partidária de idéias, opiniões de alguém e a segue pelo valor que ela atribui diante do mesmo. Com base nisto, entende-se que ser disciplinado é ter um comportamento dependente de regras e para construir a disciplina em sala de aula é preciso conquistar o aluno despertando sua admiração.

Assim, a definição do que seja considerada boa disciplina depende também dos princípios do professor, por exemplo: se o aluno faz brincadeiras contando histórias engraçadas pode ser considerado um problema para alguns, para outros pode ser apenas características de pessoa extrovertido e comunicativo. Segundo Telma Vinha (2005, p.48): 
O aluno indisciplinado não é mais aquele que conversa ou se movimenta na sala. É o que não tem limites, não respeita os sentimentos alheios, tem dificuldade em se autogovernar. (...) Em vez de um pré-requisito, a disciplina se tornou um dos objetivos a ser construídos pela escola.

Achar que só existe uma maneira de se fazer correto, um único modelo a ser seguido e assegurado obrigatoriamente, determinado pela vontade pessoal do professor é manter uma postura intransigente e inflexível.

Deste modo, percebe-se que indisciplina é uma situação de conflito e enfrentamento entre aluno/aluno e aluno/professor, percebidas por problemas comportamentais como agressão em sala, vandalismo, xingamento, bagunça etc. Embora não sejam as únicas manifestações são as que mais se destacam.

Disciplina não pode ser imposta nem ser mecanismo de repressão e de controleeducação para obediência e jamais para contestação-que muitas vezes submete o aluno a normas autoritárias, que pode desenvolver dependência, passividade e medo e até mesmo o contrário, desejo do aluno de confrontar e atacar a pessoa do professor. Portanto, ter domínio e autoridade sem ser autoritarista é sem dúvida um grande desafio para o educador. Mas o que leva um aluno, ou uma turma a ser indisciplinada?

\section{Como surge a indisciplina?}

Ao contrário do que muitos pensam a falta de disciplina não é um problema exclusivo do aluno, ou decorrente da ausência de limites em casa. Esperar deles um comportamento obediente as normas, como uma inclinação própria ou voluntária e até mesmo herdada é um erro. Para Lino Macedo (Revista Escola, p.24) "quem considera a disciplina uma coisa que se tem ou não se tem possui uma visão moralizante-que transforma uma competência numa questão de valor. (...) Essa visão atribui culpa em caso de indisciplina”. Ao colocar a responsabilidade para terceiros a escola retira-se do seu papel.

É preciso primeiramente conhecer o aluno e os fatores que desencadearam a indisciplina que podem ser, conforme Franco Barbosa (2008: p.12-14): 
- Hiperatividade: problema de natureza neurológico e genético que faz com que, inconscientemente, os alunos sejam inquietos, belisquem os outros, conversem durante as explicações e tenham déficit de atenção.

- Síndrome do Pensamento Acelerado- SPA: estudado pelo psiquiatra Augusto Cury abordada no livro Pais Brilhantes Professores Fascinantes, esta síndrome seria uma hiperatividade de natureza não genética que cria uma compulsão por novos impulsos, desejando aliviar a ansiedade gerada tornam-se inquietos, não se concentram e perturbam os colegas. Podendo também causar irritabilidade, agressividade, aversão a rotina e sintomas psicossomáticos.

- Falta de motivação do profissional: os nossos professores em grande maioria se encontram estressado, devido ao excesso de trabalho em busca de compensar a má remuneração, o número elevado de alunos em cada sala e conseqüentemente gera um desinteresse pela turma deixando-os a vontade, sem impor limites e sem ter o menor compromisso com a educação. Escolas sem uma direção atuante capaz de resolver situações conflitantes, e que tenham um ambiente hostil podem também contribuir para diminuição na qualidade de vida e de trabalho do educador.

Já Cândida (apud Áurea Lopes, 2005: p.46) associa a disciplina em três aspectos: metodologia, conteúdo e relações interpessoais, pois segundo a mesma eles causam uma desmotivação seja pela técnica desenvolvida para abordagem do conteúdo, seja pelo desinteresse pela matéria e até mesmo antipatia ao próprio docente. Mas também que o grande embaraço do docente em lidar com a indisciplina provém de sua formação que muitas vezes não lhe indica caminhos para que possa superar as dificuldades e a própria escola não tem projetos que contemple a disciplina e então o professor se encontra sozinho para enfrentar o desafio.

\section{O que podemos fazer para limitar a indisciplina?}

A sociedade por um longo período esperou que as instituições de ensino fossem um lugar de submissão, doutrinação e domesticalização e para atender a esta expectativa a escola adotava um comportamento autoritário e repressivo como instrumento disciplinador. Para se fazer obedecer recorria-se freqüentemente a castigos, ofensas, suspensão e até agressões físicas como puxões de orelha e as famosas palmatórias. De acordo com Rosângela Oliveira 
(2007) a partir de 1970, com campanhas que defendiam o fim da violência, a punição a criança com castigos físicos foi vista como ação condenável e considerado crime já na década de 80. Em 90 com a elaboração do Estatuto da criança e do adolescente o uso foi abolido.

Atualmente não se admite nenhuma destas atitudes violentas e o uso de qualquer castigo físico aplicado ao aluno pode ser considerado crime. Porém, o que fazer se o dilema da indisciplina é cada vez mais pertinente na realidade escolar?

Estamos numa época de valorização e de defesa da democracia, cidadania e respeito. Com foco nestes termos logo no inicio do período letivo, o núcleo gestor e o corpo docente, discutirão regras que deverão ser cumpridas durante o ano letivo como o cumprimento de horário, proibição de alunos nos corredores, uso da farda, proibição da entrada de alunos embriagados e tudo que possa causar a indisciplina em geral.

Posteriormente sugere-se estabelecer um diálogo, que considera a opinião e sugestão do aluno a fim de firmar um contrato Pedagógico que oriente o que é bom para todos. Com esta abertura os estudantes são convidados a propor regras comuns de convívio que definam o que é considerado errado e que sanções podem ser aplicadas em caso de descumprimento como, perdas de pontos, atividades extras, multas pagas com a doação de material de limpeza para a escola entre outras punições que devem ser sugeridas por todos.

Cabe ao professor também buscar novas propostas pedagógicas que contemplem a adoção de atividades estimulantes e interativas, para que uma aula expositiva não se torne cansativa. Cada disciplina tem maneiras mais adequadas para o seu desenvolvimento, dependendo da situação pode ser o silêncio ou a discussão em grupo a melhor estratégia.

Compreendendo esta responsabilidade de desenvolver habilidades e a personalidade nos discentes, despertando compreensão e amor, Franco Barbosa (idem, p.19-30) faz algumas sugestões de como lidar com alguns problemas específicos de indisciplina como:

- Bagunça: identificada como uma desordem geral na sala de aula, onde ninguém se compreende. Além da criação coletiva de regras o professor deve contemplar conteúdo, metodologia e um relacionamento afetuoso com o aluno.

- Embriaguês Relacional: termo adotado pelo especialista Içami Tiba que diz respeito à reunião de um grupo de alunos no final da sala com ou sem o intuito de bagunçar. A primeira medida a ser adotada é a separação da "panelinha" e a segunda é estabelecer a criação do já citado Contrato Pedagógico que limita as regras a serem seguidas. 
- Vandalismo: destruição patrimonial da escola como quebrar banheiros, cadeiras, lançar a merenda nas paredes, pichar muros, etc. Ocorre quando não há o respeito recíproco entre direção/alunos e que pode ser inibido ao estabelecer que os alunos assumam as conseqüências das suas ações. Seja ressarcindo materialmente, seja com a prestação de serviços comunitários dentro da escola.

- Agressividade: O professor precisa estar preparado emocionalmente e psicologicamente para enfrentar qualquer ataque violento. Aproximar-se do aluno, sondá-lo para encontrar a origem do problema e cativá-lo. A manifestação de agressão pode ser um descarregamento de alguma dificuldade enfrentada na vida pessoal e ao contrário do item anterior não deve ser punido (o que poderia agravar ainda mais o quadro, despertando a revolta), mas enfatizar o diálogo e em último caso buscar a orientação educacional e auxílio de um psicólogo.

- Conversas Paralelas: Embora comum entre crianças e adolescente, este tipo de conversa pode afetar o bom andamento da aula. Para ajudá-lo, aconselha-se organizar a sala em formato de "U" ou em círculo e colocar os mais inquietos próximos dos mais calados.

Em resumo, é preciso o professor refletir sobre sua prática, observar cada aluno, tentar cativá-los e incitar o respeito mútuo entre alunos e professor, discutindo com eles a elaboração de um regulamento, respeitando-o e fazendo-os respeitar.

\section{Conclusão}

O presente estudo buscou analisar os impasses e conflitos que tornam caótico o ambiente da sala de aula- a indiscplina- apontando possíveis causas para o desencadeamento da mesma e sugestões do que o docente pode fazer para efetivação de uma disciplina democrática.

Alguns aspectos relevantes referem-se à necessidade de estabelecer regras de convívio, ensinando as noções de limite e respeito, e de buscar a resolução dos conflitos recorrendo ao diálogo, introduzido de forma gradativa, como resultado de reflexões e trocas de experiências.

De um modo geral, diante de qualquer ato de indisciplina é exigido do professor boa formação pedagógica e didática para enfrentar as diversidades e adversidades em sala de aula, bem como sensibilidade e bom senso para identificar com clareza o problema; coerência na 
conduta aplicada, autoridade e rigor no empreendimento de esforços para punir e conseqüentemente limitar as ações.

Neste sentido o professor deve fazer uma análise crítica de sua prática enquanto educador, a fim de verificar uma possível mudança em sua maneira de atuar e buscar promover no espaço da sala de aula um espaço marcado por respeito, construção do diálogo e participação de todos, assim poderemos observar uma alteração dos comportamentos em sala de aula.

Portanto, tendo em vista a necessidade de se ter cada vez mais e pesquisas que abordem a indisciplina no ambiente escolar, esperamos que este estudo colabore na ampliação dos conhecimentos teórico-prático sobre o tema, ao passo que este trabalho não se encerra aqui, sugerimos a implementação de novos estudos, a fim de que possamos conhecer outras idéias de atores deste processo como alunos, pais e professores para a construção da sala de aula como lugar acolhedor e propício para o desenvolvimento cognitivo, afetivo, moral e social dos discentes.

\section{Referências:}

BARBOSA, Franco, Como superar o problema da indisciplina na escola e na sala de aula, Juazeiro do Norte, Gráfica Nobre, 2008.

LOPES, Áurea, Revista Escola, São Paulo: Ed. 183, Fundação Victor Civita, junho/julho, 2005.

MACEDO, Lino, Revista Escola, São Paulo: Ed. 183, Fundação Victor Civita, junho/julho, 2005.

VASCONCELLOS, Celso dos S., Os desafios da indisciplina em sala de aula e na escola, São Paulo: FDE, 1997 www.crmariocovas.sp.gov.br

OLIVEIRA, Rosângela, Quem nunca deu à mão a palmatória: www.educacional.blogspot.com, 2007.

Sobre as autoras:

(1) Maria Cláudia Rodrigues de Lima é Licenciada em Pedagogia e Especialista em Psicologia Aplicada à Educação pela Universidade Regional do Cariri - URCA.

E-mail: rodrigue.se@hotmail.com. 
(2) Silvana Santos Filgueiras é Licenciada em História e especialista em História e Sociologia pela Universidade Regional do Cariri - URCA.

(3) Patrícia Lima Cordeiro é Licenciada em História e especialista em História e Sociologia pela Universidade Regional do Cariri - URCA.

Como citar este artigo (Formato ISO):

LIMA, Maria Cláudia R.; FILGUEIRAS, Silvana S; CORDEIRO, Patrícia L. A Indisciplina em sala de aula. Id on Line Revista de Psicologia, Novembro de 2009, vol.1, no.10, p.06-12. ISSN 1981-1189. 